\title{
Tratamento cirúrgico da hipertrofia clitoriana
}

\author{
Surgical treatment of clitorian hypertrophy
}

\author{
Aymar Edison Sperli ${ }^{1}$ \\ José Octávio Gonçalves de \\ FREITAS $^{2}$
}

Alieksei Clairefont de Andrade Mello 3

Trabalho realizado nos Serviços Integrados de Cirurgia Plástica (MEC, SBCP) - Hospital Ipiranga, São Paulo, SP, Brasil.

Artigo submetido pelo SGP (Sistema de Gestão de Publicações) da RBCP.

Artigo recebido: 19/11/2010 Artigo aceito: 23/5/2011

\begin{abstract}
RESUMO
Introdução: Segundo vários autores, a hipertrofia discreta do clitóris está presente em $25 \%$ das mulheres. Quando o volume passa a incomodar no ato sexual, acompanhado ou não de distúrbios psicológicos, as pacientes buscam inicialmente ajuda de ginecologistas ou endocrinologistas e não raramente são encaminhadas à cirurgia plástica para a resolução dos problemas. Método: Nossa experiência é baseada em 9 pacientes, durante 15 anos, portadoras de genitália ambígua, submetidas a tratamento cirúrgico. Foram selecionados 3 casos para ilustrar os resultados obtidos com a técnica. Duas pacientes com hipertrofia clitoriana do tipo II de Prader foram selecionadas; uma de origem adquirida na idade adulta, e outra de origem possivelmente congênita. A terceira paciente apresentava anomalias sexuais múltiplas, de origem congênita: agenesia de vagina, hipertrofia clitoriana, presença de ovários e testículos atrofiados, pseudo-hermafroditismo feminino, catalogada como tipo $\mathrm{V}$ de Prader. Todos os três pacientes foram submetidas a redução do clitóris pela dissecção da cobertura músculo-cutânea (desenluvamento) e sepultamento do corpo clitoriano por sutura. Resultados: Os procedimentos cirúrgicos realizados preservaram a estética e a sensibilidade, com redução das dimensões do clitóris. Conclusão: Os procedimentos apresentam relativa simplicidade, porém dentro de critérios cirúrgicos buscando a preservação das funções e da anatomia da genitália externa.
\end{abstract}

Descritores: Clitoris/cirurgia. Vulva/cirurgia. Genitália feminina/cirurgia.

\begin{abstract}
Introduction: Moderate clitoris hypertrophy has been described in $25 \%$ of the women. When its shape and volume disturb at the sexual activity, combined or not by psychological problems, initially patients search for help from gynecologists and or by endocrinologists and not rarely are send to plastic surgeons. Our experience is based on 9 patients with ambiguous external genitalia, submitted to these surgeries during the last 15 years. Three cases were selected to demonstrate the obtained results with the technique. Two female patients with Prader type II clitoris aspect were selected; one of them presents the problem at adult age and, in the other, the etiology was possible congenital. The third patients presented hypertrophic clitoris combined with pseudo-hermaphroditism with ovarium, atrophic testicles as described in Prader Type V. Methods: The all three patients were submitted to clitoris reduction by dissection of the mucous-cutaneous covering and its excess buried by suture. The third patient with pseudo-hermaphroditism had also neo-vagina reconstruction. Results: The surgical procedures preserved esthetic and sensibility, with clitoris dimensions reduction. Conclusion: The surgical procedures presented moderate simplicity, but within the surgical criteria to preserve the functions and the external genitalia anatomy.
\end{abstract}

Keywords: Clitoris/surgery. Vulva/surgery. Genitalia, female/surgery.

1. Membro Titular da Sociedade Brasileira de Cirurgia Plástica; Regente dos Serviços Integrados de Cirurgia Plástica do Hospital Ipiranga, São Paulo, SP, Brasil.

2. Membro Titular da Sociedade Brasileira de Cirurgia Plástica; Cirurgião Plástico dos Serviços Integrados de Cirurgia Plástica do Hospital Ipiranga, São Paulo, SP, Brasil.

3. Médico residente dos Serviços Integrados de Cirurgia Plástica do Hospital Ipiranga, São Paulo, SP, Brasil. 


\section{INTRODUÇÃO}

Segundo Sayer et al. ${ }^{1}$, a hipertrofia discreta do clitóris é descrita em $25 \%$ das mulheres normais. Quando o volume é evidente e quando passa a incomodar no ato sexual, as pacientes buscam ajuda inicial com os ginecologistas ou endocrinologistas para investigação. Por circunstâncias várias, não raramente são depois encaminhadas aos cirurgiões plásticos.

$\mathrm{O}$ clitóris hipertrofiado pode ser congênito ${ }^{1-3}$, sendo, portanto, evidente ao nascimento, ou tornar-se hipertrófico na puberdade em diante. A forma congênita é predominante sobre a adquirida, contudo, existem casos relatados de causa idiopática ${ }^{4}$. Na maioria dos casos congênitos, a patologia está relacionada com o aumento dos níveis séricos dos hormônios androgênicos (testosterona, progesterona) ingeridos pelas gestantes, tumores virilizantes (de ovário, células de Leydig, etc), hiperplasia adrenal congênita, carcinoma de suprarrenal, luteoma gravídico e alguns tipos de cromossomopatias ${ }^{1-3,5}$ relacionadas a estados intersexuais.

As causas adquiridas são mais raras, podendo ser consequência do uso exógeno de hormônios androgênicos, tipo anabolizantes ${ }^{6,7}$, os tumores virilizantes, neurofibromatose, síndrome do ovário policístico e drogas anticonvulsivantes ${ }^{5}$.

\section{Anatomia}

Segundo Sobotta ${ }^{8}$, o clítoris ou clitóris está localizado no trígono urogenital do períneo e, juntamente com o monte do púbis, lábios maiores e menores, vestíbulo da vagina, bulbo do vestíbulo e as glândulas vestibulares, forma a vulva. Segundo Lean et al. ${ }^{3}$, o clitóris é homólogo ao pênis, sendo também um órgão erétil, estando encoberto pelos lábios menores da vulva, quando flácido. Consiste de uma raiz e um corpo com dois corpos cavernosos e a glande. Está situado na comissura vulvar anterior, sob a junção dos dois lábios menores que formam o prepúcio do clitóris. A face inferior do clitóris é escavada num pequeno canal que dá inserção a pregas cutâneas dos lábios menores que formam o seu freio. Tem um ligamento suspensor semelhante ao do pênis. São ligamentos fibroelásticos que o compõe, descem da linha alba e da sínfise pubiana, terminando na fáscia do clitóris ${ }^{8}$.

Os corpos cavernosos são constituídos de tecido trabeculado, com capacidade erétil, separados por uma densa bainha fibrosa sob a forma de um septo incompleto. Ambos os corpos cavernosos são envoltos por uma lâmina fibroelástica também chamada túnica albugínea. Diferente do pênis, não apresenta tecido esponjoso, não sendo atravessado pela uretra, que ocupa uma posição caudal ao órgão. Os bulbos vestibulares apresentam-se como duas massas de tecido alongado e erétil, localizados lateralmente ao óstio vaginal, profundamente aos músculos bulbos-esponjosos, que no sexo masculino constitui uma estrutura única na linha média. A vascularização do clitóris é dada pelas artérias dorsal e profunda do clitóris, ramos das artérias pudendas internas. A drenagem venosa é feita pelas veias homônimas, que seguem o trajeto do feixe vásculo-nervoso (Figura 1).

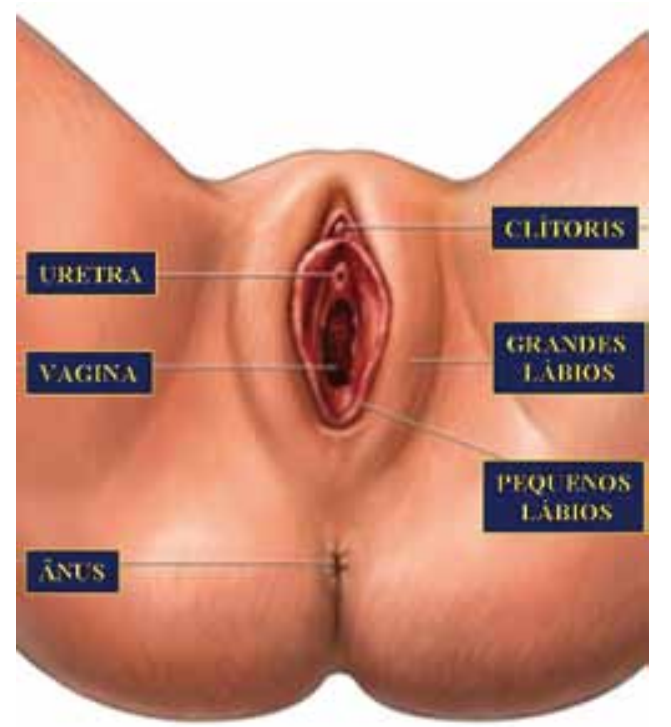

Figura 1 - Estruturas anatômicas esquemáticas da área vulvar.

Assim como o pênis, o clitóris está inserido à sínfise púbica pelo ligamento suspensor. Outra diferença refere-se à ocorrência dos bulbos vestibulares, duas massas de tecido alongado e erétil, localizadas lateralmente ao óstio vaginal, profundamente aos músculos bulbo-esponjosos, que no sexo masculino constituem uma estrutura única na linha mediana.

A nutrição do clitóris é dada pelas artérias dorsal e profunda do clitóris, que são ramos das artérias pudendas internas, cujo trajeto é posterior aos ramos clitorianos ${ }^{8}$. A drenagem venosa é feita por veias homônimas, mantendo o trajeto do feixe vásculo-nervoso. À semelhança do pênis, o clitóris é altamente importante no estímulo sexual feminino. Como possui muitas terminações nervosas, principalmente nervo dorsal e nervos cavernosos, é bastante sensível a estímulo tátil, pressão e temperatura.

Por mecanismo semelhante ao observado no homem, o clitóris sofre mecanismo de ereção na vigência de estímulo parassimpático. Ocorre relaxamento das arteríolas dos corpos cavernosos, favorecendo afluxo de sangue e ingurgitamento do tecido, embora normalmente não se observem grandes variações no diâmetro do órgão ${ }^{2}$. À semelhança do pênis, o clitóris é altamente importante ao estímulo sexual. Pelas múltiplas terminações nervosas, é também elevada a sensibilidade tátil, à pressão e à temperatura.

A síndrome de Prader-Willi (SPW) ${ }^{4,9}$ é um distúrbio neurocomportamental que geralmente surge por uma deleção proximal do cromossomo 15 durante a gametogênese paterna. Apesar da classificação de Prader ter sido elaborada, em 1954, para hiperplasia congênita de suprarrenal (HCSR), ela pode ser utilizada nos dias de hoje e pode ser ampliada para outros casos de ambiguidade genital. Prader classificou as genitálias externas das pacientes com HCSR de acordo com 
o grau de virilização que essas meninas sofriam ${ }^{4}$, do mais leve (Prader I) até o mais virilizado (Prader V):

- Prader I - aumento isolado do clitóris, indicando que a virilização tenha ocorrido após 20 semanas de vida intrauterina (VIU);

- Prader II - aumento do clitóris associado a um intróito vaginal em forma de funil, podendo visualizar-se aberturas uretral e vaginal distintas, indicando virilização iniciada com 19 semanas de VIU;

- Prader III - aumento de clitóris associado a um intróito profundo, em forma de funil, com a uretra esvaziando-se na vagina, como um pseudo seio urogenital. Há vários graus de fusão lábio-escrotal indicando uma virilização ocorrida com 14-15 semanas de VIU;

- Prader IV - clitóris fálico com abertura urogenital em forma de fenda na base do falo, indicando virilização ocorrida com 12-13 semanas de VIU;

- Prader V - fusão lábio-escrotal completa e uretra peniana, indicando virilização ocorrida com 11 semanas de VIU.

\section{MÉTODO}

Nossa experiência baseia-se no tratamento e acompanhamento de nove casos de hipertrofia simples do clitóris (Tabela 1), ou associadas a outros distúrbios característicos dos estados intersexuais, como agenesia da vagina, genitália ambígua com vulva anômala, testículos e ovários atrofiados, associados ou não a caracteres sexuais secundários (pilificação facial, androgênese somática, voz grave, etc). Foram selecionados três pacientes da nossa casuística, cada uma com suas características peculiares anatômicas e psicossociais.

\section{Técnica Cirúrgica}

Todas as cirurgias foram realizadas com as pacientes em posição ginecológicas, sob anestesia geral, infiltração local com lidocaína a $0,5 \%$, com adrenalina $1 / 100.000$ e sondagem vesical, com a finalidade de manter a urina fora do campo operatório, além de melhor orientar a dissecação transoperatória $^{10-12}$.

Paciente 1 - M.A.S, 42 anos de idade, cor parda e multípara (seis gestações, com três abortos), classificada como tipo II de Prader, de possível etiologia adquirida. A paciente veio encaminhada pelo serviço de endocrinologia após avaliações, não sendo encontrada causa objetiva da hipertrofia (Figura 2).

A principal queixa, aumento do clitóris notado há 6 anos, tinha como antecedente pregresso história de depressão e epilepsia. Fazia uso crônico de triptanol e carbamazepina. O exame físico identificava hipertrofia de clitóris, não sendo notados outros sinais de virilização da vulva (Prader II) e ausência de massas palpáveis no canal inguinal. A investigação laboratorial não identificou alteração hormonal. Tomografia do abdome e pelve foi negativa para tumor intracavitário. Neste caso, questiona-se a possibilidade idiopática ou a influência de droga anticonvulsivante como provável causa do aumento do clitóris.

A cirurgia compreendeu uma incisão circular de acesso entre o prepúcio e a glande do clitóris, aplicada a todos os

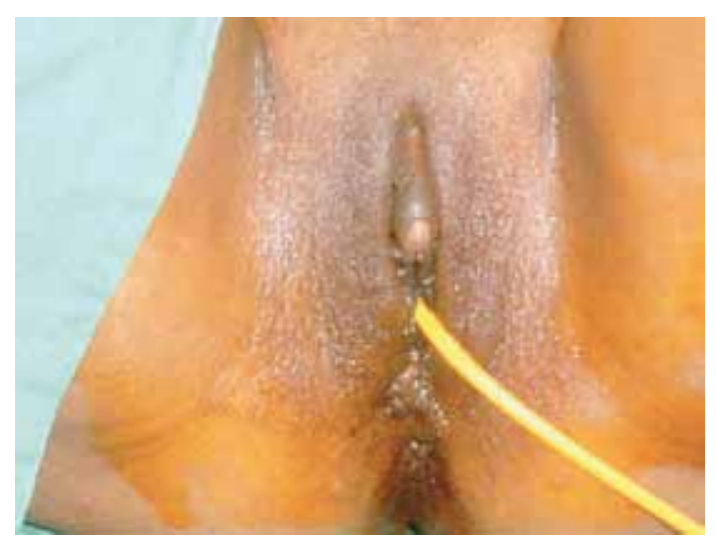

Figura 2 - Aspecto pré-operatório da paciente 1, onde se observa evidente hipertrofia do clitóris (tipo II de Prader).

Tabela 1 - Caracterização da amostra.

\begin{tabular}{c|c|c|c|c}
\hline Paciente & Tipo Prader & Ano da operação & Pós-operatório tardio & Índice de Satisfação \\
\hline M.J.S. & II & 1978 & 90 dias & Bom \\
\hline I.S.A & II & 1979 & 90 dias & Bom \\
\hline M.A.C. & II & 1982 & 90 dias & Bom \\
\hline A.M.F. & II & 1983 & 90 dias & Bom \\
\hline R.C. & V & 1985 & 90 dias & Bom \\
\hline M.A.O & II & 1987 & 90 dias & Bom \\
\hline A.M.S. & II & 1989 & 60 dias & Bom \\
\hline M.A.S. & II & 2005 & 30 dias & Bom
\end{tabular}




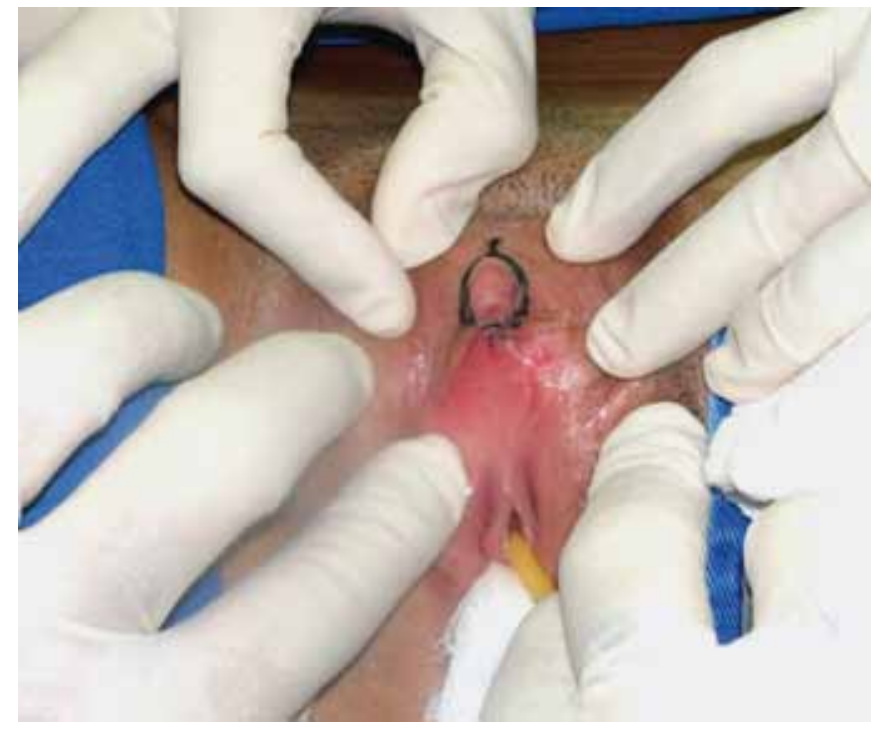

Figura 3 - Demarcação da incisão circular de acesso entre o prepúcio e a glande do clitóris (paciente 1). demais pacientes submetidos ao mesmo procedimento de redução do clitóris (Figura 3).

Realizada dissecação dos corpos cavernosos em toda a sua extensão, no plano da fáscia clitorídea, caracterizada por uma lâmina fibroelástica, até a sua base, mediante exposição e visão direta por afastamento dos tecidos ao redor. Ressecção dos excessos deste tecido (Figura 4).

A Figura 5 ilustra a ninfoplastia dos pequenos lábios da vulva com a ressecção dos excessos e sutura com pontos isolados com fio absorvível 4-0.

O reposicionamento do corpo do clitóris foi realizado mediante sutura em quatro segmentos a partir da base até a base da glande. Nos segmentos profundo, médio e superficial dos corpos cavernosos, foram aplicados em cada um deles quatro pontos isolados com fio não absorvível 4-0 entre a fáscia dos corpos cavernosos e o tecido conjuntivo circundante para a ancoragem do clitóris na posição desejada. Na sutura externa, que fixa o clitóris no nível dos pequenos lábios, foram aplicados pontos isolados de fio absorvível 4-0 (Figura 4J).
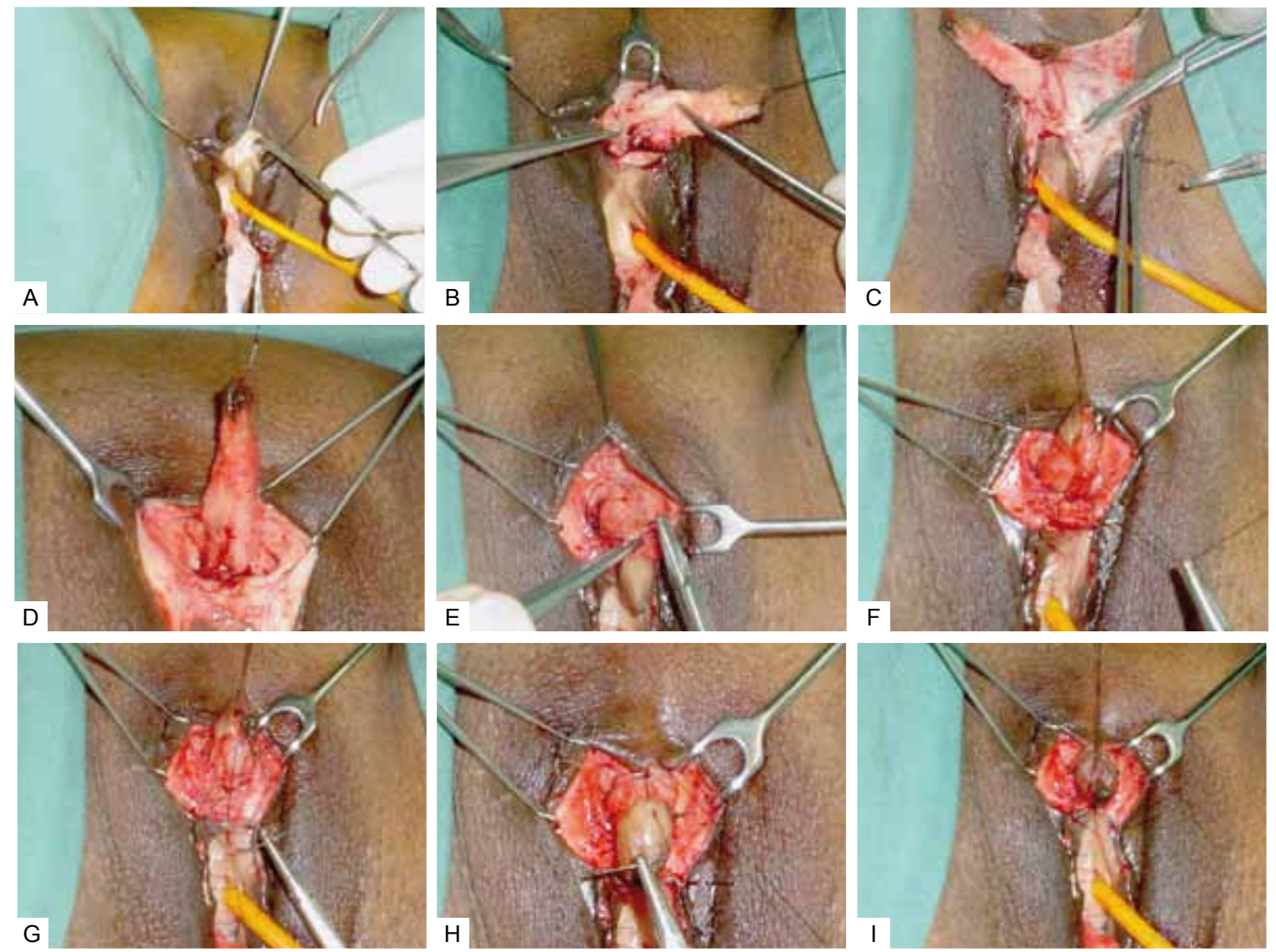

Figura 4 -A-I: Exposição do clitóris com os corpos cavernosos dissecados até a raiz, com o espaço cilíndrico em torno de tecidos circundantes. E-H: Detalhes da sutura do corpo do clitóris em três níveis da profundidade até abaixo da glande mediante 4 pontos isolados de fio não absorvível 4-0 em cada um deles. O quarto nível de sutura é o da glande do clitóris a pele dos pequenos lábios com pontos isolados de fio absorvível 4-0. I-J: Aspecto final da redução clitoriana, demonstrando os elementos da vulva (paciente 1). 


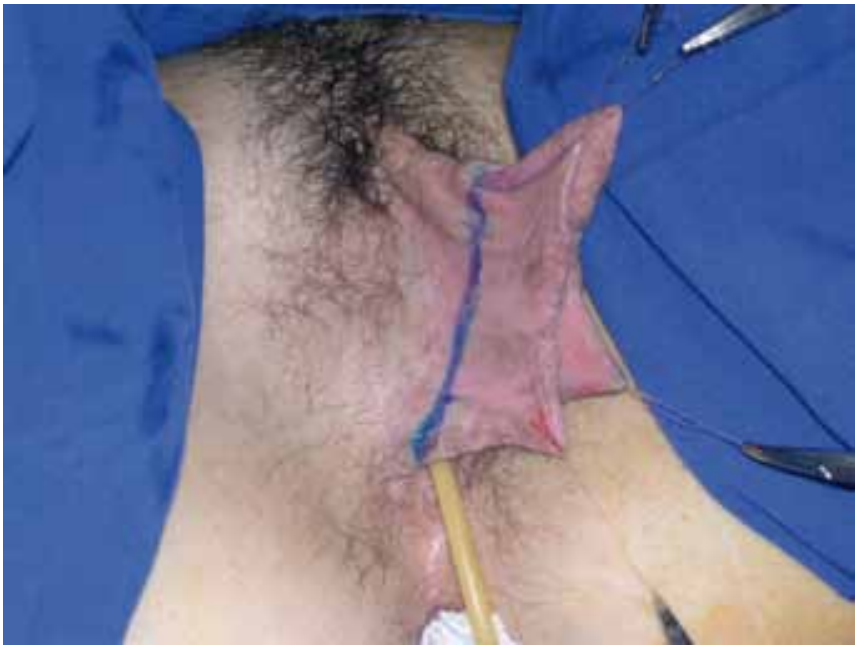

Figura 5 - Ninfoplastia dos pequenos lábios da vulva com a ressecção dos excessos e sutura com pontos isolados com fio absorvivel 4-0 (paciente 1).

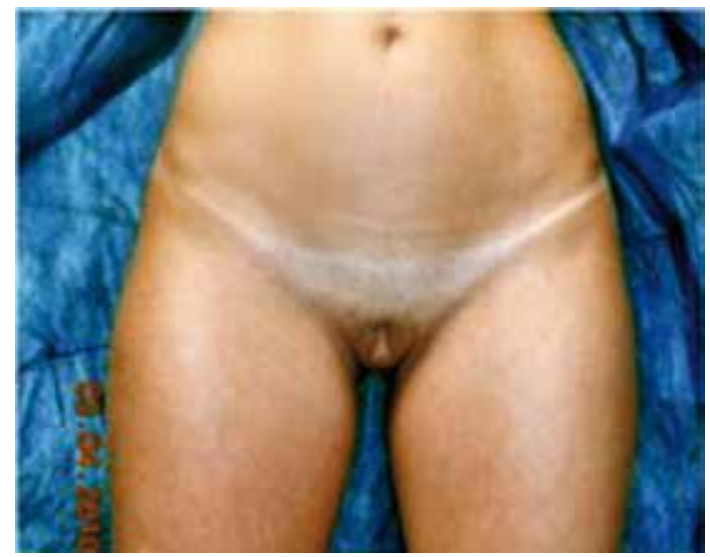

Figura 6 - Vista anterior do pré-operatório da paciente de 22 anos de idade, com clitóris hipertrófico tipo II de Prader, exteriorizado na vulva (paciente 2).

Paciente 2 - Y.O.Y, 24 anos de idade, raça amarela, nulípara, operada previamente sem sucesso de hipertrofia do clitóris, sem antecedentes do uso de medicamentos anticonvulsivos. Ao exame físico, a paciente apresentava hipertrofia do clitóris tipo Prader II, sem sinais de virilização e com exames de imagem normais. Foi considerada provável causa congênita (Figura 6).

A cirurgia seguiu os mesmos detalhes técnicos descritos na paciente anterior (Figura 7).

Paciente 3 - R.C., 46 anos de idade, caucasiana, nulípara, testículos presentes e atrofiados, pseudo-hermafrodita feminino, gônada palpável numa bolsa lábio-escrotal e fusão labial inferior. Foi tratada pela equipe multidisciplinar do
Hospital do Ipiranga, São Paulo, Capital, psicologicamente direcionada e registrada com toda documentação específica como sendo do sexo feminino (Figura 8). Esta paciente foi classificada como tipo V de Prader, de causa congênita.

A cirurgia seguiu os mesmos procedimentos técnicos aplicados aos casos descritos anteriormente (paciente 1 e 2) no tratamento da redução do clitóris, com a inclusão de dois outros procedimentos, inclusive com a confecção da neovagina pela técnica de $\mathrm{McIndoe}^{13}$ e ressecção dos testículos anômalos. A dissecção do espaço entre a uretra e o reto foi realizada com tesoura de Metzenbaum, feita com bastante cuidado, para se evitar a secção dessas áreas nobres. A pele total utilizada para enxertia (neocavidade vaginal) foi retirada da coxa direita, com dermátomo elétrico. As gônadas que podem ser visibilizadas na Figura 8 foram ressecadas, e os ovários foram mantidos. Neste caso, não houve a necessidade de ninfoplastia (Figuras $8 \mathrm{C}-\mathrm{F}$ ).

Dentre as 9 pacientes operadas, todas foram acompanhadas por um período mínimo que variou de seis meses a três anos.

\section{RESULTADOS}

Os procedimentos cirúrgicos realizados preservaram a estética e a sensibilidade, com redução das dimensões do clitóris.

As Figuras 2 a 8 ilustram os resultados obtidos com o procedimento.

O índice de satisfação das pacientes com o procedimento pode ser observado na Tabela 1.

\section{DISCUSSÃO}

Segundo Sayer ${ }^{1}$, apesar de $25 \%$ das mulheres apresentarem hipertrofia do clitóris de graus variados, a sua redução cirúrgica tem recebido pouca divulgação na literatura médica, possivelmente por se tratar de atividade multidisciplinar em alguns casos, nem sempre fácil de conciliar diferentes especialistas. Importante nestas cirurgias é a preservação das suas características fisiológicas e não a amputação da estrutura com as respectivas consequências ${ }^{2,3,5}$. Sendo constituído de corpos cavernosos e sem tecido esponjoso, os clitóris hipertróficos quando estimulados sofrem ereção, com constrangimentos para suas portadoras. Bellamy et al. ${ }^{14}$ preconizam a extirpação dos corpos cavernosos com, praticamente, a amputação da porção terminal do clitóris, o que ocasionará diminuição ou mesmo abolição da sensibilidade clitoriana.

Esta técnica de decorticação e invaginação dos corpos cavernosos tem propiciado resultados naturais e elevada satisfação às nossas pacientes ao longo dos 15 anos em que temos empregado ${ }^{10-12}$. 


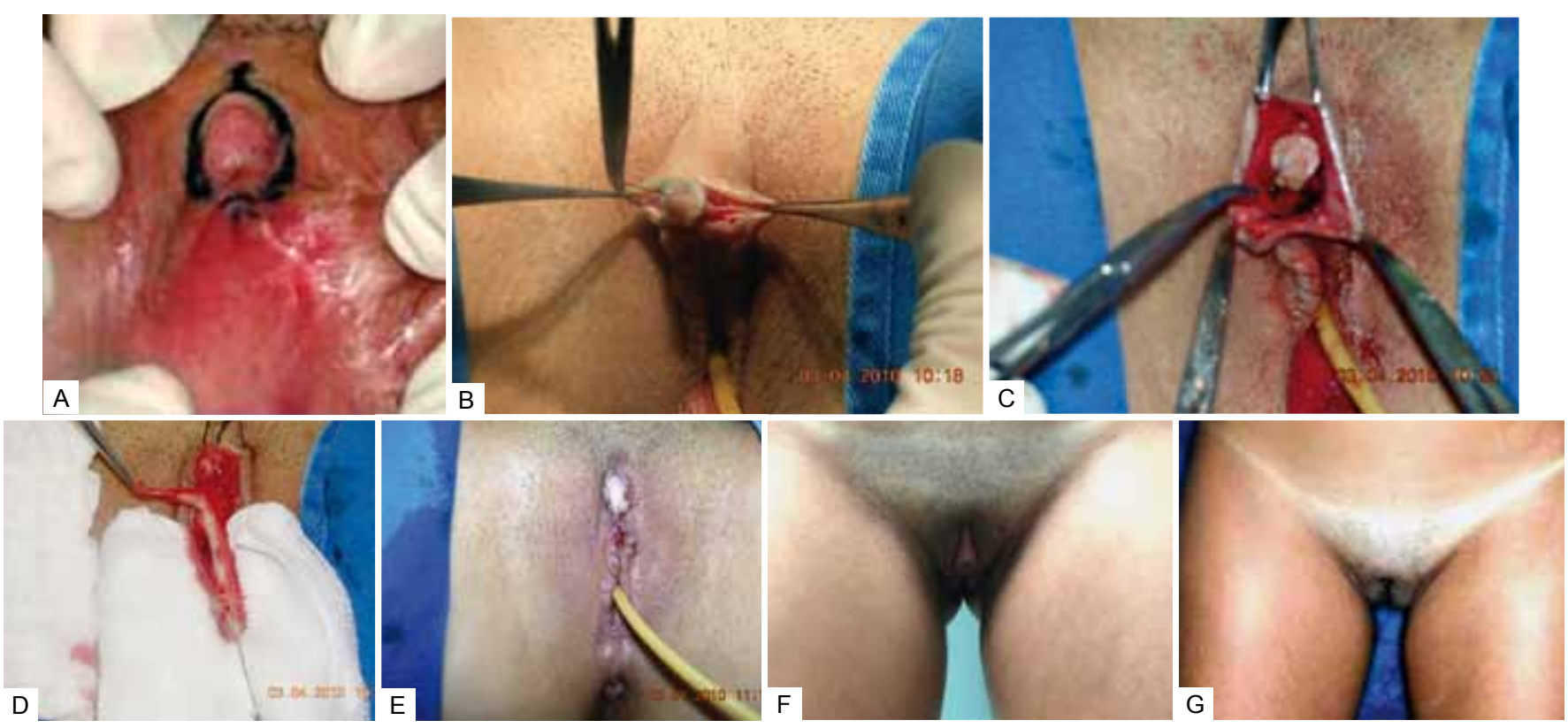

Figura 7 - Etapas de demarcação dos limites de incisão do clitóris, dissecação dos corpos cavernosos, ressecção dos excessos fibrosos e sutura por planos para "encurtamento" e sutura do clitóris na pele novamente. A: Demarcação periglande. B: Isolamento da glande. C: Dissecção do corpo do clitóris. D: Decorticação. E: Pós-operatório imediato. F: Pré-operatório. G: Pós-operatório de 60 dias (paciente 2).


Figura 8 -A e B: Aspecto físico da paciente de 48 anos de idade e da vulva ambígua, com grande hipertrofia do clitóris similar ao de um pênis de pequeno tamanho. $\boldsymbol{C}$ e $\boldsymbol{D}$ : Transoperatório para novo posicionamento do corpo do clitóris dissecado. $\boldsymbol{E}$ : Transoperatório de neovagina pela técnica de McIndoe. F: Pessário revestido com enxerto de pele - futura cavidade vaginal (paciente 3). 


\section{CONCLUSÃO}

A redução do clitóris hipertrófico, mediante sepultamento cirúrgico com a preservação dos corpos cavernosos, tem mantido efeitos estéticos e funcionais da genitália externa.

\section{REFERÊNCIAS}

1. Sayer RA, Deutsch A, Hoffman MS. Clitoroplasty. Obstet Gynecol. 2007;110(2 Pt 2):523-5.

2. Selvaggi G, Ressa CM, Ostuni G, Selvaggi L. Reduction of the hypertrophied clitoris: surgical refinements of the old techniques. Plast Reconstr Surg. 2008;121(5):358e-61e.

3. Lean WL, Hutson JM, Deshpande AV, Grover S. Clitoroplasty: past, present and future. Pediatr Surg Int. 2007;23(4):289-93.

4. Miller NL, Wevrick R, Mellon PL. Necdin a Prader-Willi syndrome candidate gene, regulates gonadotropin-releasing hormone neurons during development. Hum Mol Genet. 2009;18(2):248-60.

5. Mustafa R, Hashmi HA, Ullah S. Congenital adrenal hyperplasia causing clitoromegaly. J Coll Physicians Surg Pak. 2008;18(6):378-9.

6. Mandal S, Dhingra K, Gupta P, Khurana N. Acquired (idiopathic) intradermal nevus with junctional activity presenting as clitoromegaly in a child: report of a case. Eur J Pediatr. 2009;168(11):1405-7.
7. Pascual-Castroviejo I, Lopez-Pereira P, Savasta S, Lopez-Gutierrez JC, Lago CM, Cisternino M. Neurofibromatosis type 1 with external genitalia involvement presentation of 4 patients. J Pediatr Surg. 2008;43(11):1998-2003.

8. Sobotta J. Atlas de Anatomia Humana. $13^{\text {th }}$ ed. Philadelphia:Lippincott Williams Wilkin.

9. Damiani D, Setian N, Kuperman H, Manna TD, Dichtchekenian V. Genitália ambígua: diagnóstico diferencial e conduta. Arq Bras Endocrinol Metab. 2001;45(1):37-47.

10. Sperli AE. Tratamento cirúrgico do intersexo. In: XXXV Congresso Brasileiro de Cirurgia Plástica. Rio de Janeiro:Sociedade Brasileira de Cirurgia Plástica;2000.

11. Sperli AE, Freitas JOG. Tratamento cirúrgico da hipertrofia clitoriana. $47^{\circ}$ Congresso Brasileiro de Cirurgia Plástica. Vitória:Sociedade Brasileira de Cirurgia Plástica;2010.

12. Sperli AE, Freitas JOG. Tratamento cirúrgico da hipertrofia clitoriana. Trabalho concorrente ao Prêmio Antonio Prudente no $47^{\circ}$ Congresso Brasileiro de Cirurgia Plástica. Vitória:Sociedade Brasileira de Cirurgia Plástica;2010.

13. Saraf S, Saraf P. McIndoe vaginoplasty: revisited. Internet J Gynecol Obstetr. 2007;6(2). Disponível em: http://www.ispub.com/journal/ the_internet_journal_of_gynecology_and_obstetrics/volume_6_number 2 6/article/mcindoe vaginoplasty revisited.html

14. Bellamy ND, Wang MQ, Matthew RF, Leitão MP, Agee RA, Yan AF. Structural model analysis of HIV risk behaviors among sexually active minority adolescents. J Natl Med Assoc. 2008;100(8):914-24.

\section{Correspondência para: Aymar Sperli}

Av. Açocê, 174 - Moema - São Paulo, SP, Brasil - CEP: 04075-020

E-mail: aymar.sperli@uol.com.br 